\section{Universal biology}

\section{Richard Dawkins}

Artificial Life: The Quest for a New Creation. By Steven Levy. Cape / Pantheon: 1992. Pp. 390. £16.99, \$25.
I AM enthusiastic about the embryonic field of artificial life and want to be positive about Steven Levy's book. So let me get the minor carping out of the way first.

“...scientist Harold Thimbleby, a computer scientist at Stirling University...." The adjectival noun is ugly as well as superfluous but journalist Steven Levy, a journalist, is apparently obliged by union rules to shove it in, together with "evolutionary biologist William Hamilton", "Nobel-laureate Niko Tinbergen" and countless others.

The adjectival noun is just a trivial diagnostic of journalese. But Levy also tests positive for that more serious malady of science journalists, Dark Ages syndrome. There is a new wave of heroic young scientists (the ones the journalist has been interviewing and hanging out with). Before they burst on the scene we were mired in the Dark Ages. Left over from the Dark Ages are the Old Guard, traditional scientists with attitudes as hard as their arteries, who control the university jobs and the grant money. Our story is one of doughty deeds by the New Heroes, in the teeth of uncomprehending hostility from the Old Guard.

Occasionally, to be sure, scientific revolutions really do work like this; and in the case of artificial life its luminaries come trailing genuinely swashbuckling pasts: Doyne (pronounced Doan) Farmer and Norman Packard, who typed with their toes on ultra-miniature computers hidden in their shoes in order to Wolfram, who contemptuously forsook Eton and Oxford and created Mathematica, one of the most admired computer another boy-wonder, who invented the legendary Connection Machine; and the éminence rouge of 'Artificial Life', Christopher Langton himself, who broke all four limbs and most other bits too as an exhibition hang-glider. But the Dark Ages/Young Buccaneer formula has become a lazy cliché among science journalists, and we need to see less of it.

Levy doesn't fall into this cliché quite as heavily as some of his colleagues whose books range from anti-evolution to palaeontology to chaos theory. But he too cannot resist the temptation:

Traditional computer scientists had no trouble ticking off reasons why this could not possibly work; they cited mathematbreak the bank at Las Vegas; Stephen programs ever written; Danny Hillis, ical principles that theoretically limited the

This is a set-up, of course, for a New Hero to come bounding on-stage and confound the establishment, and Hillis duly does. But it is an unsatisfying way of writing, because a mathematical principle is a mathematical principle and we are left wondering how even the Old Guard managed to get it so wrong.

Genetic algorithms could generate robust programs and artificial adaptive phenomena by utilizing the power of evolution. Yet the lords of computer science were slow to bestow their blessings on it...

Who are these 'lords' and do the rest of us really so obsequiously grant them the power to 'bestow blessings'?

In the past, the prejudice against mathematical modeling in theoretical biology might have been justified.

What prejudice against mathematical modelling? What does Levy think theoretical biology mostly is, if not mathematical modelling? See any back issues of Journal of Theoretical Biology.

Enough of griping, let us turn this into an interesting point. There is a prejudice lurking in theoretical biology, but it is speed gain of parallel processing. not against mathematical modelling. It is more pernicious than Levy realizes, and artificial life goes right to its heart. It is a prejudice against the very idea of a truly theoretical biology, against a biology that strays far from the narrow path of 'data'. I first recognized this prejudice in 1982, at the Darwin Centenary Conference in Cambridge. I presented a paper called "Universal Darwinism", in which I argued that darwinian natural selection is not just the principle that happens to underlie life on this planet; natural selection is a necessary feature of life anywhere. If organized, apparently purposeful complexity is found anywhere in the Universe, I suggested, some form of Darwinism will be the ultimately responsible force.

In the discussion my lecture was vehemently attacked, not by any Old Guardee but by a distinguished biologist and statistician. It wasn't that he disagreed with the thesis of Universal Darwinism; if he had, that would have been interesting. No, his complaint was that I had not backed up my claim with data! You might as well attack Pythagoras because he didn't sally out into the field and measure a statistical sample of right-angled triangles. In print after the conference, my paper was assailed on similar grounds as "philosophical" - a sufficiently pejorative epithet in some scientific circles. I didn't realize it then because the phrase had not been coined, but my little essay on Universal Darwinism was grounded in the same philosophy as the now aspirant field of artificial life. It is because of this philosophy that we should take the field

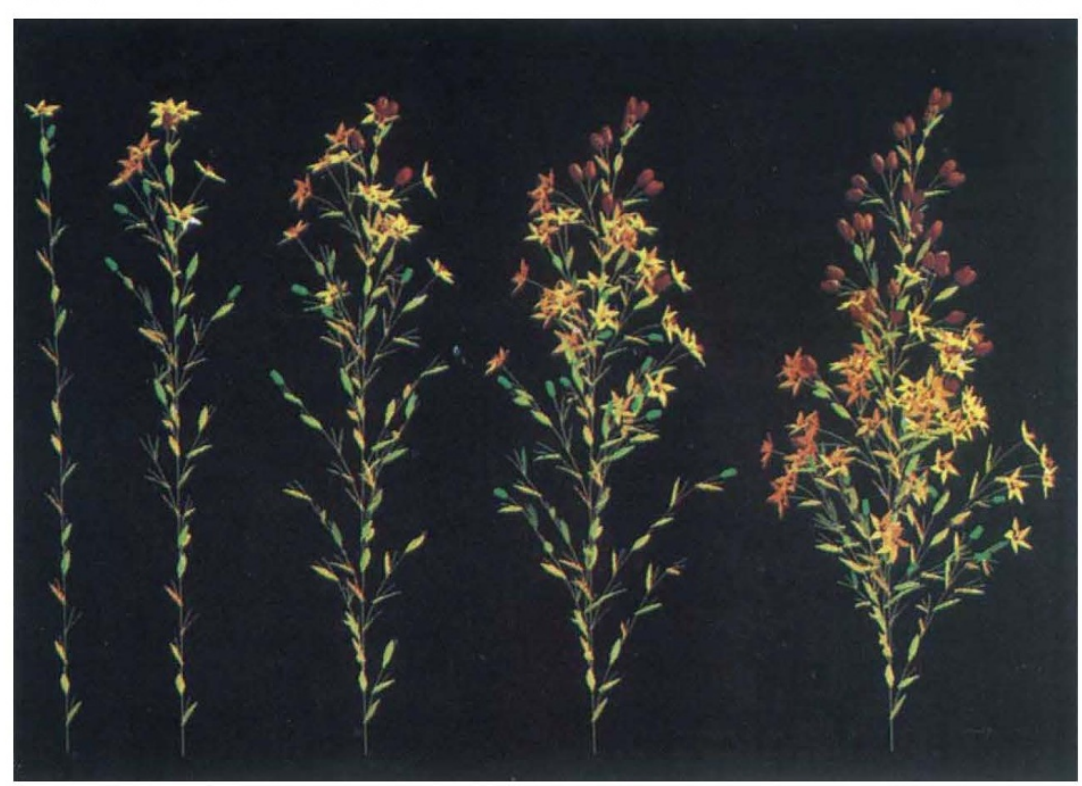

Plant programming - P. Prusinkiewicz simulated this Mycelis muralis using an L-system program, which adds self-similar new growth with each iteration of the formula. The picture is taken from the colourfully illustrated Fractals: The Patterns of Chaos by John Briggs (Simon and Schuster, $\$ 20$ (pbk)). 